\title{
Typhonium trilobatum Demonstrates Both Antioxidant and Acetylcholinesterase Inhibitory Activities In vitro
}

\author{
Simin Shabnam Lopa, Md. Kamrul Hasan, Md. Salim Ahammed, KM Monirul Islam, \\ A.H.M. Khurshid Alam, Md. Aziz Abdur Rahman, Mamunr Rashid and Golam Sadik
}

Department of Pharmacy, University of Rajshahi, Rajshahi-6205, Bangladesh

(Received: November 12, 2018; Accepted: December 27, 2018; Published: January 17, 2019)

\begin{abstract}
Alzheimer's disease (AD) is a progressive neurodegenerative disorder of the elderly people. Cholinergic dysfunction and oxidative stress have been found to be related with the development of the disease. Typhonium trilobatum $\mathrm{L}$. Scott has been used traditionally in folk medicine as a central nervous system stimulant. In this study, we have investigated the various extracts of $T$. trilobatum for acetylcholinesterase and antioxidant activities in vitro. All the tested extracts exhibited inhibition against acetylcholinesterase. Petroleum ether extract exhibited the highest inhibition with an $\mathrm{IC}_{50}$ of 255.26 $\mu \mathrm{g} / \mathrm{ml}$. Likewise all the extracts were found to possess antioxidant activity. In reducing power assay, petroleum ether extract showed the highest reducing power with an absorbance of 0.874 at $0.1 \mathrm{mg} / \mathrm{ml}$ concentration and in DPPH radical scavenging assay, chloroform extract exhibited the highest scavenging activity with an $\mathrm{IC}_{50}$ of $619.54 \mu \mathrm{g} / \mathrm{ml}$. Phytochemical analyses of the four extracts revealed that the ethyl acetate extract contained the highest amount of flavonoids and petroleum ether had the highest amount of phenolics. These results suggest that $T$. trilobatum has both antioxidant and cholinesterase inhibitory activities, which may be useful in reducing the risk of AD.
\end{abstract}

Key words: Alzheimer's disease, Typhonium trilobatum, acetylcholinesterase inhibition, antioxidant activity.

\section{Introduction}

Alzheimer's disease (AD) is a degenerative disease of the central nervous system and most prevalent among the elderly people. AD patients present a progressive loss of the cholinergic synapses associated with reduction of acetylcholine levels in the hippocampus and cortex of the brain (Davies et al., 1976; Terry et al., 2003). This has been found to be linked to the development of dementia in $\mathrm{AD}$ (Bierer et al., 1995). Therefore, inhibition of acetylcholinesterase, which enhances the concentration of acetylcholine at the synapse and improve the cholinergic deficit, is a therapeutic target for the development of drug for AD. Until now, out of the four drugs approved by the US Food and Drug Administration (FDA) to treat $\mathrm{AD}$, three are cholinesterase inhibitors such as donepezil, galantamine and rivastigmine and the rest one is memantine, a partial NMDA receptor antagonist (Graham et al., 2017). These drugs are only effective in symptomatic relief but cannot completely cure the disease. Moreover, their use is limited due to their considerable side effects (Tanaka et al., 2008). There are increasing evidences to suggest that oxidative stress is associated with the pathogenesis of AD (Lyras et al., 1997; Galasko et al., 2010). It has been shown that oxidative damage to the neurons presumably precedes neuropathology associated with AD (Nunomura et al., 2001), suggesting that the intake of antioxidant might be beneficial in preventing or treating $\mathrm{AD}$. As $\mathrm{AD}$ is a complex and multifactorial disease, the current strategy is to develop a compound with multiple targets, and plants are an important source of these compounds.

Correspondence to: Md. Golam Sadik; E-mail: gsadik2@yahoo.com 
Typhonium trilobatum, is a perennial herb belonging to the family Araceae, and widely distributed throughout Bangladesh. It is a popular leafy vegetable and being common, it is less pricey and so is consumed by poor people. It is an important source of vitamin such as thiamine, niacin, carotene and folic acid (Paul et al., 2011; WHO, 1990). Traditionally the plant is used in the treatment of different ailments. The whole plant is indicated for CNS-related conditions, as tonic and as a CNS stimulant in motor disorder. It is also used in snake bite, dermatitis, piles, boil, body ache, rheumatoid arthritis, edema, piles, helminthiasis, liver disease and spleen enlargement (Kirtikar et al., 1999; Vattyacharzo et al., 1989; Ghani, 2003). Medicinal uses of this plant have been described well in both Unani and Ayurvedic systems of medicine. Scientific investigations revealed that the plant has antimicrobial, antioxidant, anti-inflammatory, and nematocidal activities (Halder et al., 2011; Kandhasamy et al., 2008; Chattopaddhyay et al., 1989; Ali et al., 2012). Given the ethnomedicinal uses of this plant, we have undertaken to evaluate the acetylcholinesterase inhibitory activity and antioxidant property of the extracts from $T$. trilobatum.

\section{Materials and Methods}

Chemicals: DPP (2, 2'-diphenyl-1-picrylhydrazyl), aluminum chloride, ammonium molybdate, potassium ferricyanide, catechin, Folin-ciocalteu reagent, Tris- $\mathrm{HCl}$ and triton $\mathrm{X}-100$ were obtained from Sigma-Aldrich, India. Gallic acid was obtained from Wako Pure Chemical Company Ltd., Japan. 5,5'-dithio-bis-(2-nitro) benzoic acid (DTNB), acetylthiocholine iodide, and donepezil were obtained from Sigma-Aldrich, Japan. Unless otherwise specified, all other chemicals were of analytical grade.

Plant materials: The stem and leafs of $T$. trilobatum were collected from University of Rajshahi campus, Rajshahi, Bangladesh, and identified by an expert taxonomist. A voucher specimen was submitted to the herbarium of the
Department of Botany, Rajshahi University.

Extraction and isolation: Dried powdered leafs and stem (300 gm) of T. trilobatum were extracted exhaustively with methanol by cold extraction method. The extract was then filtered and concentrated with a rotary evaporator under reduced pressure at $50^{\circ} \mathrm{C}$ temperature to afford the crude methanol extract $(12.0 \mathrm{gm})$. An aliquot $(10 \mathrm{gm})$ of the concentrated methanolic extract was partitioned by the method as described earlier and the resultant partitionates that is petroleum ether (PEF, $5.05 \mathrm{gm}$ ), chloroform (CLF, $1.28 \mathrm{gm}$ ), ethylacetate (EAF, 2.63 $\mathrm{gm})$ and aqueous (AQF, $0.9 \mathrm{gm}$ ) extracts were obtained and used for the experiment purpose.

Phytochemical screening of the plant extract: Preliminary qualitative analysis of the extracts were carried out to determine the presence of various phytochemicals which include tannins, phenolics, flavonoids, alkaloids, saponins, steroids and glycosides in accordance with the methods as described earlier (Assaduzzaman et al., 2014).

Determination of total phenolic content: The total phenolic content of the various extracts of $T$. trilobatum was determined using the Folin-Ciocalteu reagent (Singleton et al., 1999). $0.5 \mathrm{ml}$ of plant extract or solution of reference standard at different concentrations was added to $2.5 \mathrm{ml}$ of Folin ciocalteu (diluted 10 times with water) reagent and $2.5 \mathrm{ml}$ of sodium carbonate $(7.5 \%)$ solution. The reaction mixture was incubated for 20 minutes at $25^{\circ} \mathrm{C}$ and the absorbance of the final mixture was measured at $760 \mathrm{~nm}$. Gallic acid was used as reference standard and the results were expressed as $\mathrm{mg}$ of gallic acid equivalent (GAE)/gm of dried extract.

Determination of total flavonoid content: Total flavonoid content of the various extracts of $T$. trilobatum was determined by aluminum chloride colorimetric method using catechin as a standard (Zhishen et al., 1999). The extract $(1.0 \mathrm{ml})$ was added to $3.0 \mathrm{ml}$ of methanol, $0.2 \mathrm{ml}$ of $10 \% \mathrm{AlCl}_{3}, 0.2 \mathrm{ml}$ of $1 \mathrm{M}$ potassium acetate and $5.6 \mathrm{ml}$ of distilled water. The resulting mixture was then incubated at room temperature for 30 minutes and the absorbance of the 
mixture was measured at $420 \mathrm{~nm}$. Catechin was used as standard. The results were expressed as $\mathrm{mg}$ of catechin equivalent (CE)/gm of dried extract.

Determination of ferric reducing antioxidant power (FRAP): The FRAP of the plant extracts of $T$. trilobatum was evaluated by the method as described earlier (Oyaizu 1986). The extract or standard solutions at different concentration $(1 \mathrm{ml})$ were mixed with $2.5 \mathrm{ml}$ each of potassium buffer $(0.2 \mathrm{M})$ and potassium ferricyanide $(1 \% \mathrm{w} / \mathrm{v})$. The resulting mixture was incubated for 20 minutes at $50^{\circ} \mathrm{C}$ followed by addition of $2.5 \mathrm{ml}$ of trichloro acetic acid $(10 \% \mathrm{w} / \mathrm{v})$ solution. The mixture was centrifuged at $3000 \mathrm{rpm}$ for 10 minutes to collect the upper layer. $2.5 \mathrm{ml}$ of solution from upper layer was mixed with $0.5 \mathrm{ml}$ of ferric chloride $(0.1 \% \mathrm{w} / \mathrm{v})$ solution and $2.5 \mathrm{ml}$ of distilled water and. The absorbance of the solution was then measured at 700 $\mathrm{nm}$. Catechin was used as standard for comparison.

Determination of DPPH radical scavenging activity: DPPH radical scavenging activity of the extracts of T. trilobatum was determined according to the method as described earlier (Choi et al., 2000). 2 $\mathrm{ml}$ of methanol solution of the extract or standard at different concentration was mixed with $3 \mathrm{ml}$ of methanol solution of DPPH $(0.135 \mathrm{mM})$ into the test tube. The reaction mixture was incubated at room temperature for 30 minutes in dark place and the absorbance of the solution was measured spectrophotometrically at $517 \mathrm{~nm}$. DPPH free radical scavenging ability (\%) was calculated by using the formula:

$\left[\left(\mathrm{A}_{\text {absorbance of control }}-\mathrm{A}_{\mathrm{absorb} a n c e}\right.\right.$ of sample $) / \mathrm{A}_{\mathrm{absorbance}}$ of control $] \times 100$

Determination of acetylcholinesterase inhibitory activity: The acetylcholinesterase inhibitory assay was performed according to the colorimetric method of Ellman and associates (Ellman et al., 1961). Acetylcholinesterase enzyme was prepared from rat brain as described earlier (Asaduzzaman et al., 2014). The rates of hydrolysis by acetylcholinesterase were monitored spectrophotometrically. Each extract or standard $(500 \mu \mathrm{l})$ was mixed with an enzyme solution $(200 \mu \mathrm{l})$ and incubated at $37^{\circ} \mathrm{C}$ for $15 \mathrm{~min}$.
Absorbance at $405 \mathrm{~nm}$ was read immediately after adding an Ellman's reaction mixture $[3.5 \mathrm{ml} ; 0.5 \mathrm{mM}$ acetylthiocholine, $1 \mathrm{mM}$ DTNB] in a $50 \mathrm{mM}$ sodium phosphate buffer ( $\mathrm{pH}$ 8.0) to the above reaction mixture. Reading was repeated for $10 \mathrm{~min}$ at $2 \mathrm{~min}$ intervals to verify that the reaction occurred linearly. The blank reaction was measured by substituting saline for the enzyme. Donepezil was used as positive control. The percentage inhibition of acetylcholinesterase activity was calculated using the following formula:

$\left[\left(\mathrm{A}_{\mathrm{absorb} a n c e}\right.\right.$ of control $-\mathrm{A}_{\mathrm{absorb} a n c e}$ of sample $) / \mathrm{A}_{\mathrm{absorb} a n c e}$ of control] $\times 100$

Statistical Analysis: All analyses were carried out in triplicates. Data were presented as mean \pm SD. Free $\quad$ R-software $\quad$ version 2.15 .1 (http://www.r-project.org/) and Microsoft Excel 2007 (Roselle, IL, USA) were used for the statistical and graphical evaluations. Significant differences ( $p$-value $<0.05$ ) between the means were determined using the $t$-test.

\section{Results and Discussion}

$\mathrm{AD}$ is the major cause of dementia in the elderly people. It is a complex and multifactorial disease. Different mechanisms including amyloid and tau hypothesis, cholinergic and oxidative stress hypothesis have been proposed to explain the pathogenesis (Terry et al., 2003; Lyras et al., 1997; Masters et al., 2012). It is therefore suggested that an agent that can act on several targets would be an effective candidate as a potential drug to prevent the development of AD. In an epidemiological study, the incidence of $\mathrm{AD}$ in Indian subcontinent elderly people was found to be approximately 4.4 fold less when compared to a reference US population (Chandra et al., 2001). Environmental factors including dietary habits like intake of plant derived substances are thought to be responsible for this decreased incidence. In this context, curcumin, an ingredient of turmeric, has shown potential roles in ameliorating AD (Frautschy et al., 2010). $T$. trilobatum is a very popular vegetable consumed by 
Bangladesh, India, and Pakistan, and has been used traditionally as tonic and central nervous system stimulant (Kirtikar et al., 1999; Vattyacharzo et al., 1989; Ghani, 2003). In this study, we have investigated the different extracts of T. trilobatum for acetylcholinesterase inhibitory and antioxidant activities using in vitro models.

Acetylcholinesterase inhibitory activity: The use of acetylcholinesterase inhibitors is currently accepted as the first line pharmacotherapy for symptomatic relief of AD. Inhibition of acetylcholinesterase can enhance cholinergic transmission by reducing the enzymatic hydrolysis of acetylcholine, leading to improvement of memory and cognition (Graham et al., 2017). The effect of $T$. trilobatum on acetyl- cholinesterase was evaluated by the Ellman's method (Ellman et al., 1961) and the results have been shown in the Figure 1. All the tested extracts exhibited inhibition of acetylcholinesterase ranging from $23-65 \%$. Petroleum ether extract showed the highest activity with $\mathrm{IC}_{50}$ value of $255.26 \mu \mathrm{g} / \mathrm{ml}$. The other extracts had comparatively less activity and failed to reduce 50\% of the enzymatic activity. These results suggest that the $T$. trilobatum possesses considerable acetylcholinesterase inhibitory activity in comparing with the other medicinal plants Bacppa moneira, Centella asiatica, Convolvulus pluricaulis, Glycyrrhiza glabra, and Aegle marmelos, which are used in traditional Ayurvedic medicine for improving memory and cognitive function (Assaduzzaman et al., 2014; Mathew et al., 2014).

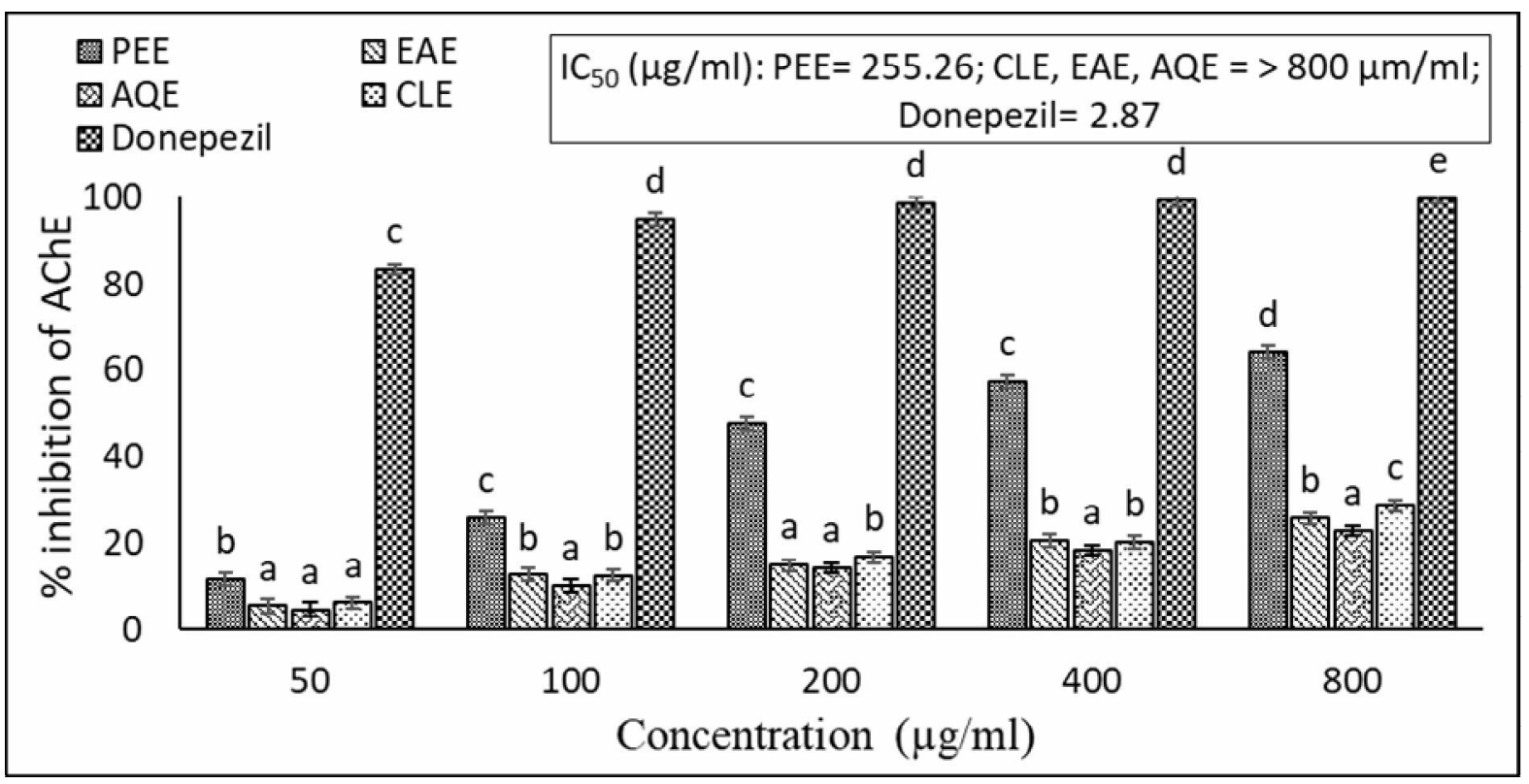

Figure 1. Acetylcholinesterase inhibitory activity of T. trilobatum extracts and standard donepezil. Results represent mean \pm $\mathrm{SD}(\mathrm{n}=3)$. Different letters $(\mathrm{a}, \mathrm{b}, \mathrm{c}, \mathrm{d}, \mathrm{e})$ indicate significant differences at $\mathrm{p}<0.05$. PEE, petroleum ether extract; CLE, chloroform extract; EAE, ethylacetate extract; AQE, aqueous extract.

Antioxidant activity: Free radical plays an important role in the pathogenesis of AD. Abeta protein is known to produce free radical and increased amount of oxidized protein, lipid and DNA has been observed in the brain of patients with $\mathrm{AD}$ (Lyras et al., 1997; Galasko et al., 2010). Naturally occurring antioxidants have been reported to play a major role in the prevention of oxidative damage induced by free radicals (Commenges et al., 2000; Darvesh et al., 2010).

Antioxidant activity of the T. trilobatum extract was evaluated by two different assays, DPPH radical scavenging assay and reducing power assay. DPPH is a stable free radical whose level decreases following 
exposure to a proton radical scavenger. The results of DPPH radical scavenging assays of the different extracts of T. trilobatum have been shown in Figure 2A. Our results demonstrated the DPPH scavenging activity of the tested extracts. Similar to acetylcholinesterase inhibitory activity, petroleum ether extract showed the highest activity followed by chloroform extract and aqueous extract with $\mathrm{IC}_{50}$ values of 529.47, 619.54, and $625.32 \mu \mathrm{g} / \mathrm{ml}$, respectively. The ethylacetate extract had comparatively less activity and failed to reduce 50\% of DPPH scavenging activity.
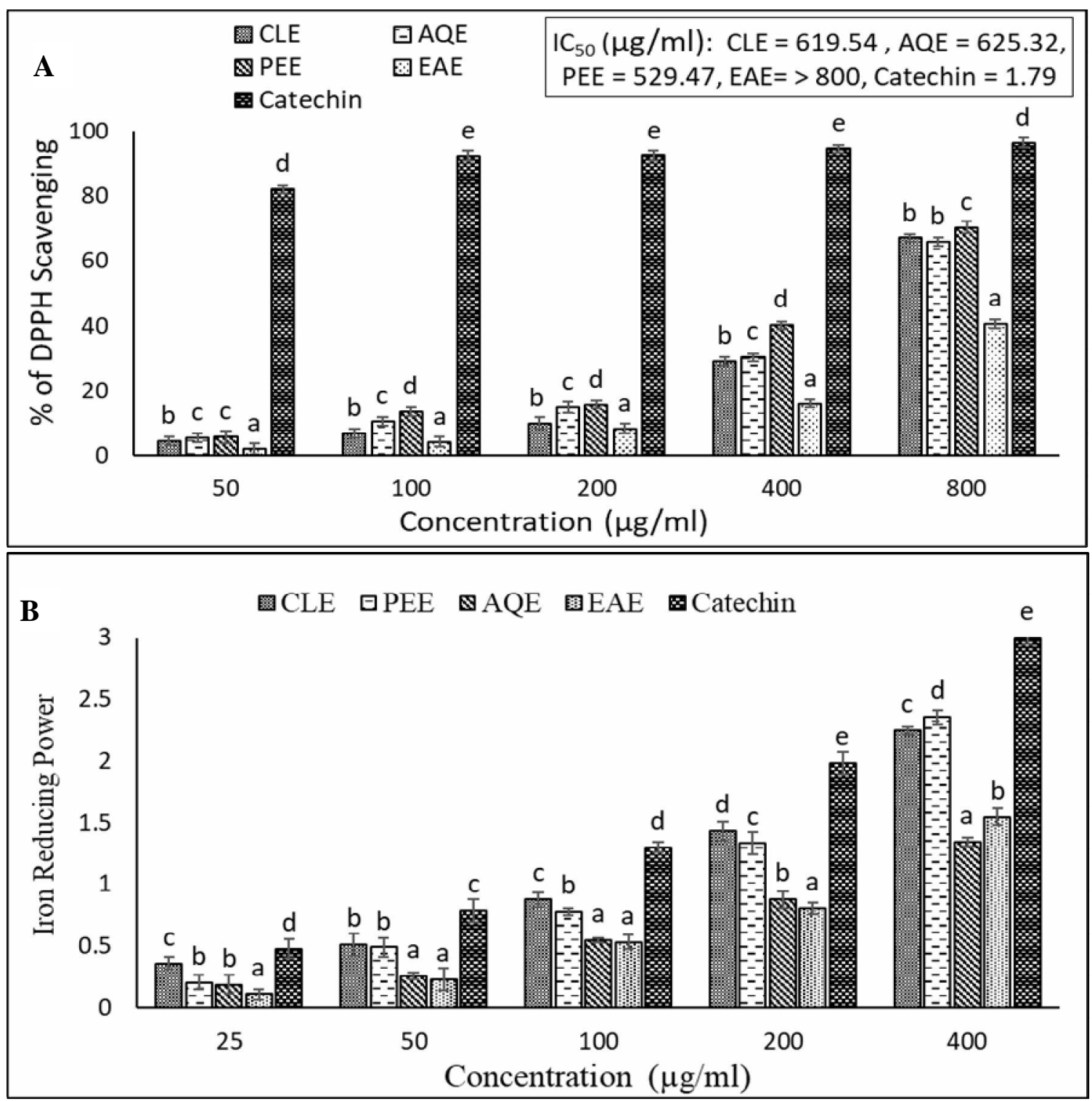

Figure 2. Antioxidant potential of T. trilobatum extracts. (A) DPPH radical scavenging activities of T. trilobatum extracts and standard catechin. (B) Reducing power of T. trilobatum extracts and standard catechin. Results represent mean \pm SD $(\mathrm{n}=3)$. Different letters $(\mathrm{a}, \mathrm{b}, \mathrm{c}, \mathrm{d}, \mathrm{e})$ indicate significant differences at $P<0.05$. PEE, petroleum ether extract; CLE, chloroform extract; EAE, ethylacetate extract; $\mathrm{AQE}$, aqueous extract; $\mathrm{CA}$, catechin.

The reducing power represents the ability of an antioxidant to donate electrons. We have assessed the reducing ability of $T$. trilobatum extract by ferric reducing antioxidant power (FRAP) method based on 
the reduction of the $\mathrm{Fe}^{3+}$-ferricyanide complex to the ferrous form. The results of the reducing power of the different extracts have been shown in Figure 2B. All the extracts increased the absorbance significantly with the increase of concentration of the extract, demonstrating the antioxidant potential of $T$. trilobatum. Chloroform extract showed the highest activity with an absorbance of 0.874 at $100 \mu \mathrm{g} / \mathrm{ml}$ concentration. Whereas the absorbance of ethylacetate, petroleum ether and aqueous extracts were $0.776,0.534$ and 0.548 , respectively at the same concentration. Ascorbic acid was used as a standard which gave an absorbance of 1.301. Taken together, our results demonstrated the appreciable antioxidant activity of the extract of $T$. trilobatum.

Table 1. Total phenolic and flavonoid contents of different extracts from T. trilobatum.

\begin{tabular}{ccc}
\hline Sample & TPC & TFC \\
& (mg GAE/g dried extract $)$ & $(m g$ CE/g dried extract $)$ \\
\hline PEE & $2.94 \pm 0.16^{(\mathrm{a})}$ & $46.53 \pm 0.21^{(\mathrm{a})}$ \\
CLE & $4.53 \pm 0.18^{(\mathrm{b})}$ & $20.94 \pm 0.35^{(\mathrm{b})}$ \\
EAE & $6.14 \pm 0.45^{(\mathrm{d})}$ & $32.87 \pm 0.57^{(\mathrm{c})}$ \\
AQE & $1.24 \pm 0.22^{(\mathrm{c})}$ & $1.88 \pm 0.19^{(\mathrm{d})}$ \\
\hline
\end{tabular}

PEE, petroleum ether extract; CLE, chloroform extract; EAE, ethylacetate extract; AQE, aqueous extract. TPC: Total phenolic content, TFC: Total flavonoid content. Means in each column with different subscript letters (a b, c, d, e, f) differ significantly ( $\mathrm{p}<0.05)$.

Phytochemical Analyses: A preliminary phytochemical analyses was conducted first to understand the presence of different classes of phytochemicals in the extract of T. trilobatum. The extracts showed the presence of phenolics and flavonoids, phytosterols, alkaloids, tannins, and saponins which is consistent with the previous study (Kandhasamy et al., 2008). Phenolics and flavonoids are important classes of phytochemicals that are reported to have antioxidant activity due to their redox properties. Quantitative analyses of the four extracts (Table 1) revealed that the ethylacetate extract contained the highest amount of phenolic $(6.14 \pm 0.45 \mathrm{mg}$ GAE/gm dried extract) followed by chloroform extract $(4.53 \pm 0.18 \mathrm{mg}$ GAE/gm dried extract), petroleum ether extract $(2.94 \pm 0.16 \mathrm{mg}$ GAE/gm dried extract) and aqueous extract (1.24 \pm $0.22 \mathrm{mg} \mathrm{GAE} / \mathrm{gm}$ dried extract). In contrast, petroleum ether contained the highest amounts of flavonoids $(46.53 \pm 0.21 \mathrm{mg} \mathrm{CE} / \mathrm{gm}$ dried extract $)$ followed by chloroform extract $(20.94 \pm 0.35 \mathrm{mg}$ CE/gm dried extract), ethyl acetate (32.87 $\pm 0.57 \mathrm{mg}$ $\mathrm{CE} / \mathrm{gm}$ dried extract), and aqueous extract(1.88 \pm $0.19 \mathrm{mg} \mathrm{CE} / \mathrm{gm}$ dried extract).

\section{Conclusion}

Results of the present study clearly demonstrated that the extract of $T$. trilobatum, has considerable amount of phenolics and flavonoids and possesses both cholinesterase inhibitory activities and antioxidant properties. These findings suggest that increasing the intake of this vegetable may be helpful in preventing or reducing the risk of $\mathrm{AD}$.

\section{References}

Ali, K., Ashraf, A. and Biswas, N. N. 2012. Analgesic, anti-inflammatory and anti-diarrheal activities of ethanolic leaf extract of Typhonium trilobatum $\mathrm{L}$. Schott. Asian Pac. J. Trop. Biomed. 2, 722-726.

Asaduzzaman, M., Uddin, M.J., Kader, M.A., Alam, A.H., Rahman, A.A., Rashid, M., Kato, K., Tanaka, T., Takeda, M. and Sadik, G. 2014. In vitro acetylcholinesterase inhibitory activity and the antioxidant properties of Aegle marmelos leaf extract: implications for the treatment of Alzheimer's disease. Psychogeriatrics. 14, 1-10.

Bierer, L.M., Haroutunian, V., and Gabriel, S. 1995. Neurochemical correlates of dementia severity in Alzheimer's disease: relative importance of the 
cholinergic deficits. J. Neurochem. 64, 749-760.

Chandra, V., Pandav, R., Dodge, H.H., Johnston J.M., Belle, S.H., Dekosky, S.T. and Ganguli, M. 2001. Incidence of Alzheimer's disease in a rural community in India: the Indo-US study. Neurology. 57, 985-989.

Chattopaddhyay, P.R., and Mukhopadhyaya, M.C. 1989. Comparative studies on the nematicidal properties of Typhonium trilobatum and Melia azedarach. Indian J. Nematol. 19, 5-9.

Choi, H.Y., Jhun, E.J. and Lim, B.O. 2000. Application of flow injection-chemilumineacence to the study of radical scavenging activity in plants. Phytoth. Res. 14, 250-253.

Commenges, D., Scotet, V., Renaud, S., Jacqmin-Gadda, H., Barberger-Gateau, P. and Dartigues, J.F. 2000. Intake of flavonoids and risk of dementia. Eur. J. Epidemiol. 16, 357-363.

Darvesh, A.S., Carroll, R.T. and Bishayee, A. 2010. Oxidative stress and Alzheimer's disease: dietary polyphenols as potential therapeutic agents. Expert Rev. Neurother. 10, 729-745.

Davies, P. and Maloney A.J.F. 1976. Selective loss of central cholinergic neurons in Alzheimer's disease. Lancet. 2, 1403.

Ellman, G.L., Courtney, K.D., Andres, V. and Feather-stone, R.M. 1961. A new and rapid colorimetric determination of acetylcholinesterase activity. Biochem. Pharmacol. 7, 88-95.

Frautschy, S.A. and Cole, G.M. 2010. Why pleiotropic interventions are needed for Alzheimer's disease. Mol. Neurobiol. 41, 392-409.

Galasko, D. and Montine, T.J. 2010. Biomarkers of oxidative damage and inflammation in Alzheimer's disease. Biomark Med. 4, 27-36.

Ghani, A. 2003. Medicinal plants of Bangladesh: Chemical constituents \& uses. $2^{\text {nd }}$ ed. Asiatic Society of Bangladesh. 1-16.

Graham, W.V., Bonita-Oliva, A. and Sakmar, T.P. 2017. Update on Alzheimer's disease therapy and prevention strategies. Annu Rev. Med. 68, 413-430.

Haldar, K.M., Ghosh, P., and Chandra, G., 2011. Evaluation of target specific larvicidal activity of the leaf extract of Typhonium trilobatum against culex quinquefasciatus say. Asian Pac. J. Trop Biomed. S199-S203.

Kandhasamy, M., and Arunachalam, K.D. 2008. Efficacy of Typhonium trilobatum (L.) Schott tuber extracts on pathogenic bacteria. Elect J. Nat. Subs. 3, $1-7$.
Kirtikar, K.R., and Basu, B.D. 1999. Indian Medicinal Plants, $2^{\text {nd }}$ edition. 4, 2606-2610.

Lyras, L., Cairns, N.J., and Jenner, A. 1997. An assessment of oxidative damage to proteins, lipids, and DNA in brain from patients with Alzheimer's disease. $J$. Neurochem. 68, 2061-2069.

Masters, C.L. and Selkoe, D.J. 2012. Biochemistry of Amyloid $\beta$-protein and amyloid deposits in Alzheimer disease. Cold Spring Harb Perspect Med. 2, 1-24.

Mathew, M., and Subramanian, S., 2014. In vitro screening of anticholinesterase and antioxidant activity of methanolic extracts of ayurvedic medicinal plants used for cognitive disorders. Plos ONE. 9, 1-7.

Nunomura, A., Perry, G., Aliev, G., Hirai, K., Takeda, A., Balraj, E.K., Jones, P.K., Ghanbari, H., Wataya, T., Shimohama, S., Chiba, S., Atwood, C.S., Petersen, R.B. and Smith, M.A. 2001. Oxidative damage is the earliest event in Alzheimer disease. J. Neuropathol Ex. Neurol. 60, 759-767.

Oyaizu, M. 1986. Studies on products of browning reactions: antioxidant activities of products of browning reaction prepared from glucose amine. Jap. J. Nutr. 44, 307-315.

Paul, A.K., Arif, H.A., Seraj, S., Nahar, A., Nasrin, D., Chowdhury, M.H., Islam, F., Jahan, R., Bashar, A.A.B.M., Freedman, R., and Rahmahatullah, M. 2011. A survey of plant items eaten by the low income groups of the rural population of Talbunia village in Bagerhat district, Bangladesh with an account of their folk medicinal applications. Advances in Natural and Applied Sciences. 5, 41-54.

Singleton, V.L., Orthofer, R. and Lamuela-Raventos, R.M. 1999. Analysis of total phenols and other oxidation substrates and antioxidants by means of Folin-Ciocalteu reagent. Meth. Enzymol. .299, 152-178.

Tanaka, T., Kazui, H., Morihara, T., Sadik, G, Kudo, T. and Takeda, M. 2008. Post marketing survey of donepezil Hydrochloride in Japanese patients with Alzheimer's disease with behavioral and psychological symptoms of dementia (BPSD). Psychogeriatrics. 8, 114-123.

Terry Jr. A.V., and Buccafusco, J.J. 2003. The cholinergic hypothesis of age and alzheimer's disease-related cognitive deficits: recent challenges and their implications for novel drug development. $J$. Pharmacol. Expt. Thera. 306, 821-827.

Vattyacharzo, S. 1989. Chironjib Bonowshodhi. 10, 178-181.

World Health Organization, 1990. Medicinal plants in Viet Nam. WHO Regional Publications, Western Pacific 
Series No. 3, WHO Regional Office for the Western Pacific, Manila. ISBN 9290611014.

Zhishen, J., Mengcheng, T. and Jianming, W. 1999. The determination of flavonoid contents in mulberry and their scavenging effects on superoxide radicals. Food Chem. 64, 555-559. 